\title{
A RESPONSABILIDADE LEGAL DO ENFERMEIRO
}

\author{
Taka Oguisso ${ }^{1}$
}

OGUISSO, T. A responsabilidade legal do enfermeiro. Rev. Bras. Enf., Brasilia, 38(2): 185-189, abr./jun. 1985.

\begin{abstract}
RESUMO. O trabalho define o termo responsabilidade no sentido geral, analisando em seguida a responsabilidade civil, penal e ética do enfermeiro à luz da legislação vigente. Identifica, a seguir, problemas que mais comumente podem advir da prática incorreta das ações assistenciais e o envolvimento do enfermeiro e seu grau de responsabilidade em relação à gravidade dos danos decorrentes. Aconselha este profissional a manter-se atualizado em relação à evolução dos conhecimentos científicos e aos aspectos éticos e legais da profissão.

ABSTRACT. The term responsibility in a general form is initially defined in this paper following of an analyse to the nurse's civil, penal and ethics responsibilities regard of actual legislation. In a second part, the author identifies the commom problems that can occur of an inaccurate practice of the assistencial actions and the nurse's implications and their level of responsibility in relation to the severity of the deriving risk. At last, advise to the nurses to keep up atualized concerning to the scientific knowledge evolution and to the ethics and legal aspects of profission.
\end{abstract}

\section{INTRODUÇÃO}

$\mathrm{O}$ rápido desenvolvimento tecnológico, vivido e sentido hoje intensamente por toda a humanidade, traz para todos uma necessidade contínua de adaptação nos hábitos cotidianos, desde o ambiente do lar. com seus eletrodomésticos cada vez mais sofisticados, até o campo da atividade profissional, invadido também por modemos aparelhos eletrônicos e pela automação.

Essas modificações nas atividades profissionais estão igualmente trazendo mudanças no papel do enfermeiro, que passam a exigir dele maior conhecimento e, conseqüentemente, acarretando aumento proporcional de responsabilidade.
Em que consistiria, então, responsabilidade?

No sentido geral, responsabilidade tem o significado de obrigação, encargo, compromisso ou dever de satisfazer ou executar alguma coisa que se convencionou deva ser satisfeita ou executada ou, ainda, suportar as sanções ou penalidades decorrentes dessa obrigação.

$\mathrm{O}$ estudo do problema da responsabilidade traz sempre em seu bojo os aspectos de dever, de dano ou de prejuízo e também de reparação do dano.

O Código de Deontologia da Enfermagem declara: "quando o ser humano se apresenta sob as vestes de um profissional, os deveres são normas de conduta que orientam o exercício de suas ativida. 1 Enfermeira e advogada. Professor Assistente Doutor da Escola de Enfermagem da USP. Chefe do Serviço de Enfer-
magem do Hospital Brigadeiro - INAMPS/SP. 
des, ńas relações dos profissionais entre si, com seus clientes e com a comunidade".

A responsabilidade envolve ainda o aspecto do dano ou do prejuízo produzido por alguém que violou direito de terceiros. Sempre que ocorrerem tais danos ou prejuizos cabe reparação, restauração, ou indenização do mal causado. Não haverá responsabilidade jurídica se a violação de um dever não produzir dano, seja pessoal, material ou moral.

\section{A RESPONSABILIDADE CIVIL, PENAL E ÉTICA DO ENFERMEIRO}

O Código Civil Brasileiro acolheu, no art. 159, o princípio do dever de reparar, dispondo: “... aquele que, por ação ou omissão voluntária, negligência ou imprudência violar direito ou causar prejuízo a outrem, fica obrigado a reparar o dano".

O Código Penal também menciona esses aspectos ao definir o crime culposo (art. 18) como sendo aquele em que o "....agente deu causa ao resultado por imprudência, negligência ou imperícia".

O Código de Infraçōes e Penalidades, promulgado pelo Conselho Federal de Enfermagem, estabelece: “...responde pela infração quem a cometer ou de qualquer modo concorrer para a sua prática, ou dela se beneficiar".

É ainda o Código Civil que postula (art. 1545): “...os médicos, cirurgiões, farmacêuticos, parteiras e dentistas são obrigados a satisfazer o dano, sempre que da imprudência, negligência ou imperícia, em atos profissionais, resultar morte, inabilitação de servir ou ferimento".

O enfermeiro não está expressamente incluido entre os profissionais relacionados, porque o Código Civil foi aprovado 1916, portanto, antes da criação da primeira escola de enfermagem, dentro do sistema moderno.

A esse respeito, é oportuna a citação de PANASCO ${ }^{11}$ que afirma: “...até bem pouco tempo, o enfermeiro possuia, em relação ao médico, uma posiçāo secundária. Atualmente, posicionando-se em nivel universitário semelhante ao do médico, sua responsabilidade adquiriu as mesmas caracteristicas deste".

Apesar de ser um dos temas mais importantes dentro da teoria e prática da responsabilidade civil, pois que é um direito cuidar dos danos à saúde, da integridade física e da vida da pessoa humana. “esse direito, afirma MAGALHÃES ${ }^{9}$ - não está ainda devidamente protegido pela doutrina e muito menos pela jurisprudência, onde os julgados, além de serem escassos, nem sempre dão como procedentes as açōes que têm como fundamento prejuizos causados por culpa profissional".

Em direito, cabe ao autor do processo o ônus da prova; em outras palavras, o prejudicado deve demonstrar a culpa do profissional.

A prova exigida é, geralmente, dificilima porque, além do provável silèncio dos outros eventuais participantes da ocorrência, a perícia judicial, muitas vezes, pronuncia-se contra o paciente. PANASCO $^{11}$, baseado em literatura estrangeira, denomina essa situaçāo de "conspiração do silêncio" ou de "confratemidade profissional", que nada tem a ver com sigilo profissional.

Voluntariamente ou não, o pessoal de enfermagem pode estar participando de forma solidária, ativa ou passiva, dessa "conspiração".

Apesar desse quadro desanimador, MAGALHÃES ${ }^{9}$ declara que "...nem tudo está perdido; porque continuam a existir ótimos, conscientes e competentes profissionais que nada têm a temer, e que também condenam os irresponsáveis que desonram a profissão". Além do mais, salienta-se o franco declínio da atitude de resignação e conformidade passiva da própria população diante de danos físicos ou pessoais sofridos e na intensa repercussão nos meios de comunicação quando da ocorrência de acidentes durante anestesia, cirurgia e outros tratamentos.

Existe também o princípio geral que não pode ser esquecido: é a questão da co-autoria. O Código Penal prevê: (art. 29): “...quem, de qualquer modo, concorre para o crime, incide nas penas a este cominadas, na medida de sua culpabilidade".

Segundo NORONHA ${ }^{10}$, na co-autoria ou co-delinqüência “...há convergência de vontades para um fim comum, aderindo uma pessoa à ação de outra, sem que seja necessário prévio ajuste entre elas".

$\mathrm{Na}$ enfermagem, o Código de Deontologia, preceitua que é proibido ao "...enfermeiro ser conivente, ainda que a título de solidariedade, com crime, contravenção penal ou ato praticado por colega que infrinja postulado ético profissional". $\left(\mathrm{COFEN}^{4}\right)$.

Embora a natureza jurídica da responsabilidade profissional constitua ainda matéria controvertida, pode-se afirmar que, quando o enfermeiro se vincula à obrigação de prestar algum serviço, são aplicados os princípios da obrigação de meio.

A obrigação de meio é aquela em que um profissional " $\because .$. se obriga a usar de prudência e dili- 
gência normais na prestaçāo de um serviço para atingir um resultado, sem contudo, se vincular a obtê-lo".

Da mesma forma, quem procura o médico, busca a recuperação de sua saúde; mas esse resultado não é objeto de contrato.

A obrigação de resultado é aquela em que o cliente tem o direito de exigir do profissional a produçāo de um resultado, como ocorre no caso de construção de obra por empreitada.

No campo da saúde, a jurisprudência já tem demonstrado a exigência de obrigação de resultado nos casos de cirurgia plástica.

\section{IMPLICAÇÕES LEGAIS NO EXERCICIO PROFISSIONAL DE ENFERMAGEM}

A Constituiçāo assegura o "livre exercício de qualquer trabalho, of ício ou profissão, observadas as condições de capacidade que a lei estabelecer".

Essa condição de capacidade não se refere, evidentemente, à capacidade ou aptidão física ou mental e nem mesmo técnica, mas a uma capacidade éstabelecida por lei.

No caso do enfermeiro, a liberdade de exercer a profissão que a Constituição garante é limitada pelas condições de capacidade estabelecida na Lei no 2.604/55.

Essa Lei prescreve que “...só poderão exercer a enfermagem, em qualquer parte do território nacional, os profissionais cujos títulos tenham sido registrados...".

A titularidade constitui condição de capacidade técnica para o exercício profissional, não apenas na enfermagem, mas também em qualquer outra profissão. Daí a importância que a legislação confere à qualidade ou ao título profissional, de acordo com o grau de preparo e formação. Portanto, na divisão do trabalho, as atividades mais complexas e de maior responsabilidade devem ser atribuídas a profissionais de maior preparo acadêmico.

Entretanto, a legislação do exercício profissional de enfermagem, ainda em vigor, permite que todas as atividades assistenciais sejam realizadas por qualquer categoria, indistintamente, sem delimitaçāo alguma por todas as categorias que com. pōem a equipe de enfermagem, embora com a ressalva de que deve ser "sempre sob orientação de médico ou de enfermeiro", excluídas as atividades administrativas e de ensino.

Além da capacidade técnica, adquirida pela formação curricular, o enfermeiro deve apresentar também capacidade legal exigida pela Constituição.

Essa capacidade legal é conferida ao profissional somente quando seu título de enfermeiro tenha sido registrado no Conselho Regional de Enfermagem, conforme previsto no art. 15 da Lei 5.905, de 12 de julho de 1973.

\section{A PRÁTICA DA ENFERMAGEM À LUZ DA LEGISLAÇÃO CIVIL, PENAL E ÉTICA}

A peculiaridade das atribuições do pessoal que lida com vidas humanas obriga que sua atuação se coadune com os preceitos dos Códigos Civil e Penal, além do respectivo Código de Ética Profissional.

Inúmeros dispositivos poderiam ser estudados e discutidos; porém, a exigüidade do espaço e a especificidade do tema oficial do I Encontro Regional de Enfermagem da Região Sudeste sugerem a escolha de matérias que se relacionem mais com os atos lesivos contra a vida, lesões corporais e alguns tópicos sobre periclitação da vida e da saúde.

$O$ enfermeiro e o pessoal de enfermagem podem ser envolvidos em crime de homicídio no exercício de suas funções?

Além dos aspectos ainda polêmicos da eutanásia, provocada através de ações deliberadas ou intencionais de desligamento de aparelhos e equipamentos, ou provocada por omissões na prestação de assistência, surgem ainda inúmeras oportunidades de formas culposas de homicídio, como autor ou co-autor. As formas culposas de crime são aquelas em que não há intenção ou vontade deliberada, mas esse fato culposo é decorrente de negligência, imprudência ou imperícia.

Injeção de substâncias estranhas, como dietas e sucos no intracatch; utilização de substâncias tóxicas ou cáușticas em enteroclisma, clister e curativos; introdução inadvertida de ar por via venosa; falta de controle quanto ao correto funcionamento de equipamentos ligados, ou a serem ligados, em pacientes; falta de vigilância permanente dos pacientes submetidos a tratamentos com certos equipamentos ou aparelhos, mesmo que eletrônicos ou automáticos, esses são alguns dos inúmeros exemplos de situações desagradáveis que podem ocorrer durante a execução de atividades de enfermagem no hospital, em ambulatório, em serviço de emergência ou mesmo em serviço a domiculio. 
O Cóciigo Penal dispõe que no "...homicídio culposo, a pena é aumentada de um terço, se o crime resulta de inobservância de regra técnica de profisão, arte ou ofício, ou se o agente deixa de socorrer a vítima ou não procura diminuir as conseqüências do seu ato...".

Como se vê, não é tão difícil ser envolvido num crime de homicídio culposo em pleno exercício da enfermagem, se não houver diligência, atenção è correta observância das regras técnicas da profissão.

A legislação penal estabelece ainda penalidades a quem "...induzir ou instigar alguém a suicidar-se, ou prestar-lhe auxilio para que o faça".

Circunstâncias especiais podem comprometer o pessoal de enfermagem, quando, por exemplo, acontece tecerem comentários inadvertidos em corredores ou mesmo em enfermarias sobre casos de prognóstico fechado ou moléstias de forte conotação emocional, como era a tuberculose e a lepra no passado, e a síndrome de imuno-deficiência adquirida (AIDS) atualmente. Tais comentários, chegando ao conhecimento do paciente, podem desesperançá-lo, levando-o à prática de suicídio. Evidentemente, não houve indução deliberada ou instigação consciente, mas sim, imprudência e leviandade que podem levar o paciente a uma atitude mais drástica e desesperada, suscitada pelos comentários ouvidos.

"Todo e qualquer dano ocasionado à normalidade funcional do corpo humano, quer do ponto de vista anatômico, quer do ponto de vista fisiológico ou mental" constitui uma lesão corporal. Portanto, a lei prevê dano à saúde que não precisa ser propriamente uma lesã̃o ao corpo. E essa lesão pode ser cometida por ação ou omissão.

As lesōes corporais são classificadas em: leves, graves, gravíssimas e seguidas de morte.

$\mathrm{Na}$ lesão leve, o dano ao corpo ou à saúde não deixa seqüela e nem incapacidade para as ocupações habituais por mais de 30 dias; exemplos: hematomas, provocação de náuseas e vômitos, não dar alimentação à boca de pessoa incapacitada de fazê-lo por si, escara de decúbito, etc.

São consideradas graves as lesões que produzem incapacidade para as ocupações habituais por mais de 30 dias, provocam perigo de vida e debilidade permanente de algum membro, sentido ou função e aceleração de parto.

No campo de enfermagem, o seu pessoal pode ser envolvido em situações que produzam: luxações, fraturas, escaras ou feridas por falta de vigi- lância; enfraquecimento, redução ou diminuiçāo de capacidade; ferimentos e contusões por queda do leito, da maca, da cadeira, etc. queimaduras por bolsa de água quente, berço excessivamente aquecido, incubadoras desreguladas, pé equino, etc. Eviden temente, o profissional que opera um desses equipamentos ou aparelhos só poderá responder pela lesão ao paciente se ficar estabelecida sua culpa. Se a lesão aconteceu em decorrência de defeito do aparelho, a responsabilidade deve ser assumida por quem realiza os serviços de sua manutenção.

São lesões gravíssimas as que geram incapacidade permanente para o trabalho, enfermidade incurável, perda ou inutilização de algum membro, sentido ou função e deformidade permanente. Exemplos: amputação de membros, ou parte deles, por gangrena causada por restrição mal feita e não vigiada ou por infiltração extravenosa de soluções hipertônicas ou tóxicas durante injeção endovenosa ou administração gota-a-gota, paresias ou paralisias por lesão de nervo em infecções, etc.

Lesōes corporais seguidas de morte são aquelas que evoluem para a morte como conseqüência da ofensa corporal. Exemplos: fratura de base de crânio por queda de maca ou mesa cirúrgica.

A título de sugestão, nos serviços de emergência com quadro insuficiente de pessoal, esse risco pode ser reduzido bastando que se solicite à familia permanecer junto ao paciente para vigiá-lo.

Algumas lesões dependem da evolução e seqüelas para suas classificação numa das categorias citadas. Uma escara, por exemplo, se tratada em tempo, pode ser curada em menos de 30 dias: nesse caso, será uma lesão leve. Da mesma forma, a administração de medicação trocada, ou medicação correta mas aplicada de forma errada em sua dosagem ou via, ou ainda em pacientes trocados as conseqüências podem ser nulas e, numa escala crescente, variar para náuseas. vômitos, choque anafilatico e até morte. $\mathrm{O}$ tipo de conseqüencia acarretado é que irá definir se se trata de lesão leve, grave, gravissima ou seguida de morte. E, de acordo com essa graduação, também a graduação da penalidade.

Da mesma forma, se um paciente contrair uma moléstia no hospital, da qual não era portador antes de sua admissão (como ocorre nos casos de infecçāo hospitalar e cruzada), a perícia técnica irá classificar a lesão corporal a partir da avaliação das seqüelas deixadas e das incacidades resultantes, isto é. se foram transitórias ou permanentes, se 
foram por mais de 30 dias ou não.

Entre os crimes considerados como de periclitação da vida e da saúde, apresentam maior relação com o tema "infecção hospitalar" os seguinteş: perigo de contágio de moléstia grave, perigo para a vida ou saúde de outrem, e maus tratos.

Constitui, pois, crime praticar ato capaz de produzir contágio, com o fim de transmitir a outrem moléstia grave de que está contaminado.

Atualmente, o portador de síndrome de imuno-deficiência adquirida (AIDS), que reage não aceitando a doença, precisa ser firmemente orientado para não transmitir a doença a outros.

Também expor a vida ou a saúde de outrem a perigo direto e iminente é uma situação que, com freqüência, pode ocorrer em ambulatórios, com problemas de esterilização de material. Por exemplo, a utilização de espéculos não esterilizados, em ginecologia, podem transmitir doenças venéreas, infecções e outros males de uma paciente para outra. Nos hospitais, igualmente podem ocorrer situaçōes semelhantes ligadas a problema de desinfecção terminal de unidade após alta ou óbito de pacientes.

O pessoal médico e de enfermagem tem possibilidade de transformar-se num veículo importante na transmissão de moléstias graves. A execução de cuidados elementares, tais como lavar as mãos após terminar os cuidados de um paciente, utilizar corretamente as técnicas de avental, gorro, etc., especialmente nos casos de isolamento reverso, podem reduzir os riscos de infecção.

Pelo Código Penal, constitui crime de maus tratos (art. 135) “...expor a perigo a vida ou a saúde de pessoa sob sua autoridade, guarda ou vigilância, para fim de educação, ensino, tratamento ou custódia, quer privando-a de alimentação ou cuidados indispensáveis..."

Na si tuação hospitalar, o pessoal de enfermagem pode incorrer nesse crime não auxiliando, por exemplo, a criança ou o paciente debilitado a se alimentar. ou não ministrando os cuidados indispensáveis de higiene e tratamentos, não assistindo às necessidades de eliminaçc̃es acarre tando com isso não apenas mal-estar e desconforto, mas, por vezes, infecçðes, sofrimento in tenso ou agravamento de sua moléstia.

Conforme as circunstâncias, essas falhas podem ser caracterizadas também como lesões corpor.iis leves ou graves.

NORONHA $^{10}$ refere que o crime de maus tratos constitui delito especial praticável pelos pais, professores e enfermeiros, entre outros, seja privando a pessoa de alimentos, seja privando de cuidados indispensáveis à saúde causando dano à incolumidade do ofendido.

\section{CONCLUSÕES}

A continuar a escala ascendente de queixas-crime, denúncias e demandas judiciais com pedido de ressarcimento por danos sofridos pelos pacientes cada vez mais esclarecidos, os profissionais da saúde terão que constituir, como sugere STREN$G^{12}$ “...um fundo de garantia e adotar um sistema automático de indenizações por danos resultantes de acidentes corporais causados pela atividade profissional".

Os enfermeiros precisam estudar e acompanhar a evolução dos conhecimentos científicos, mantendo-se atualizados, especialmente quanto às responsabilidades legais da profissão.

O Professor FAVERO 6 denominava "charlatães inconscientes os médicos estacionários que continuavam a exercer a profissão, escudados apenas na própria experiência... sem acompanhar a evolução da medicina, sem estudar, aferrados aos conhecimentos antigos, firmes em idéias atrasadas".

Quantos enfermeiros estarão nessa condição?

Sem assumir efetivamente a responsabilidade inerente à titularidade de enfermeiro, será muito difícil, se não impossível, que o público reconheça e valorize a profissão do enfermeiro.

OGUISSO, T. Nurse's legal responsability. Rev. Bras. Enf., $38(2)$ : 185-189, abr. Jun. 1985.

\section{REFERÊNCIAS BIBLIOGRÁFICAS}

1. BRASIL. Leis, Decretos, etc. Decreto-lei no 2.848 , de 7.12.40, atual. pela lei no 7.209, de 11.7.84, In: - Código penal. Organização dos textos, notas remissivas e índices por Juarez de Oliveira. 23. ed. São Paulo, Saraiva, 1985.

2. - Decretos, etc. Lei no 3.071, de 1.1.16, com as alteraçōes posteriores. In: — Código civil brasileiro. 19. ed. São Paulo, Saraiva, 1968.

3. __ Constituiçāo da República Federativa do Brasil: emenda constitucional no 1, de 17.10.69 e emendas posteriores. São Paulo. CEPAM, s/d.

4. CONSELHO FEDERAL DE ENFERMAGEM. Código de deontologia de enfermagem. Resolução COFEN no 9/75. Brasília, 1975. 
5. Código de infraçōes e penalidades. In: Conselho Federal de Enfermagem. Documentos básicos do COFEN. Rio de Janciro, 1983. p. $112 / 116$.

6. FÁ VERO, F. Código penal comentado. São Paulo, Saraiva, 1950. v. 9.

7. LEI No 2.604/55, de 17 de setembro de 1955: regula o exercício da enfermagem profissional. In: BRASIL. Ministério da Saúde. Fundação SESP. Enfernnagem, legislação e assuntos corrclatos. 3. ed. Rio de Janciro, 1974. v. 1, p. 177/179.

8. LEI No 5.905/73, de 12 de julho de 1973: dispõe sobre a criação dos Conselhos Federal e Regionais de Enfermagem e dá outras providências. In: BRASIL. Ministério da Saúde. Fundação SESP.
Enfermagem, legislaçāo e assuntos correlatos. 3. ed. Rio de Janciro, 1974. v. 3, p. 759/763.

9. MAGALHĀES, T.A.L. Responsabilidade civil dos médicos. In: CAHALI, Y.S. Responsabilidade civil - doutrina e jurisprudência. São Paulo, Saraiva, 1984. p. 309/354.

10. NORONHA, E.M. Direito penal: parte especial. 16. ed. São Paulo. Saraiva. 1980). v. 2.

11. PANASCO, W.L. A responsabilidade civil, penal $e$ ética dos médicos. Rio de Janciro. Forense, 1979.

12. STRENGER, I. Erro médico c responsabilidade. Rev. Paul. Hosp., São Paulo, 31 (5-6): 132-134, mai./ jun., 1983. 